\title{
The influence of LiDAR pulse density on the precision of inventory metrics in young unthinned Douglas-fir stands during initial and subsequent LiDAR acquisitions
}

\author{
Michael S Watt ${ }^{1 *}$, Andrew Meredith ${ }^{2}$, Pete Watt ${ }^{2}$ and Aaron Gunn ${ }^{3}$
}

\begin{abstract}
Background: LiDAR is an established technology that is increasingly being used to characterise spatial variation in stand metrics used in forest inventory. As the cost of LiDAR acquisition markedly declines with LiDAR pulse density, it is useful to identify how far pulse density can be reduced without compromising the precision of relationships between LiDAR and stand metrics. Using plot measurements and LiDAR data obtained from highly stocked and unthinned Douglas-fir plantations (Pseudotsuga menziesii [Mirb.] Franco), the objective of this research was to characterise the precision of regressions between LiDAR metrics and stand metrics (mean top height, $H_{m}$, volume, $V$ and mean diameter, D) under a range of pulse densities using Digital Terrain Models (DTMs) representing two common scenarios. Under the first scenario, which represents an initial acquisition, the point cloud was sequentially culled and used for creation of a DTM and corresponding LiDAR cloud metrics. In the second scenario, which represents a subsequent acquisition, a DTM generated at high pulse density $\left(10\right.$ pulses $\left.\mathrm{m}^{-2}\right)$ was used for the creation of the corresponding LIDAR cloud metrics.
\end{abstract}

Methods: Models describing the precision of regressions between LiDAR metrics and stand metrics were developed at 10 pulses $\mathrm{m}^{-2}$. LiDAR data were culled to pulse densities ranging from 10 to 0.01 pulses $\mathrm{m}^{-2}$ and the impact of culling on the precision of these regressions was examined under the two scenarios.

Results: For the scenario with the culled DTM, precision of the three models remained stable until densities of $2-3$ pulses $\mathrm{m}^{-2}$ were reached. Below this threshold, there was a gradual decline in precision to pulse densities of $0.7-1$ pulses $\mathrm{m}^{-2}$ at which point the $R^{2}$ was $95 \%$ of the maximum values. Further culling of the data resulted in a sharp decline in model precision for all three regressions. For the scenario where the DTM was held at a high pulse density, little change in the precision of the regressions was found until pulse densities of 0.04 to 0.2 pulses $\mathrm{m}^{-2}$ were reached. There was a sharp decline in precision below pulse densities of 0.04 pulses $\mathrm{m}^{-2}$ for all three models.

Conclusion: This study was undertaken in highly stocked unthinned Douglas-fir stands located in areas with complex topography. Consequently, the pulse density thresholds described here are likely to be conservative and could be used to guide acquisition of high-quality LiDAR datasets for this species.

Keywords: Airborne laser scanning; ALS; Forest inventory; Laser; LiDAR; Pseudotsuga menziesii

\footnotetext{
* Correspondence: michael.watt@scionresearch.com

'Scion, PO Box 29237, Fendalton, Christchurch, New Zealand

Full list of author information is available at the end of the article
} 


\section{Background}

LiDAR is an established technology used to derive spatial stand metrics that are increasing the accuracy and efficiency of operational forest inventory. Since the first application of LiDAR in forestry almost three decades ago (Nelson et al. 1984), LiDAR point cloud data have been used to accurately predict stand height (Watt and Watt 2013; Coops et al. 2007; Means et al. 2000; Næsset 2002; Means et al. 1999) and volume (Watt and Watt 2013; Coops et al. 2007; Means et al. 2000; Næsset 2002; Means et al. 1999). Correlations of moderate to high strength have been found between LiDAR metrics and basal area (Næsset 2002, 2004b, 2005; Nord-Larsen and Schumacher 2012; Means et al. 1999; Means et al. 2000), diameter (Næsset 2002) or green crown height (Næsset and Okland 2002). However, stand density is typically predicted only with a moderate degree of precision from LiDAR cloud metrics (Næsset and Bjerknes 2001; Hall et al. 2005; Næsset 2002).

As LiDAR acquisition over large areas is expensive, LiDAR missions often require compromises around data quality. One of the most important variables affecting the cost of acquisition over a fixed area is the LiDAR pulse density (Baltsavias 1999; Lovell et al. 2005). Although there are many ways to increase the pulse density (e.g. reducing aircraft altitude and speed), ultimately this variable is related to flight time (Jakubowski et al. 2013) and consequently acquisition cost increases with pulse density. It is, therefore, of considerable interest to understand how far pulse density can be reduced without unduly compromising the accuracy of inventory information obtained from LiDAR data.

The influence of pulse density on the precision of relationships between stand and LiDAR metrics has been widely investigated. In stands dominated by Norway spruce (Picea abies (L.) Karst.) and Scots pine (Pinus sylvestris L.), Gobakken and Naesset (2008) found that pulse densities could be reduced from 1.13 to 0.25 pulses $\mathrm{m}^{-2}$ with little effect on the quality of inventory results. In a mixed conifer forest, where pulse densities were reduced from 9 to 0.01 pulses $\mathrm{m}^{-2}$, it was found that correlations between LiDAR metrics and key stand metrics (tree height, diameter, and basal area) were relatively unaffected until pulse densities were reduced below 1 pulse $\mathrm{m}^{-2}$ (Jakubowski et al. 2013). In mixed conifer-hardwood stands, it was found that pulse density could be reduced from 3.2 to 0.5 pulses $\mathrm{m}^{-2}$ with little effect on the precision of relationships between LiDAR and stand metrics (Treitz et al. 2012).

Although research has investigated the extent to which pulse densities can be reduced, little work has compared how precision changes without and with a high quality digital terrain model (DTM). Generally an initial LiDAR flight is undertaken to obtain accurate representations of the ground and canopy through the respective creation of a DTM and canopy height model (CHM). Reducing the pulse density of the data too much during this initial acquisition is likely to compromise the quality of the DTM which in turn which will have a deleterious effect on estimates of canopy metrics as these are referenced to the DTM. However, once an accurate DTM has been obtained, relationships are likely to exhibit greater stability to lower pulse densities as the position of the ground to which the above-ground point cloud is referenced does not change. Although previous research has verified this effect in stands dominated by Picea abies and Pinus sylvestris (Magnusson et al. 2010), the authors are unaware of any other research that has made this comparison in plantation monocultures.

High productivity and superior wood properties have made Douglas-fir (Pseudotsuga menziesii [Mirb.] Franco) one of the premier and most widely planted plantation species throughout the world. Globally, there are ca. 15 million hectares of Douglas-fir plantations with substantial areas occurring in Europe, South America, New Zealand, Australia and western North America (Hermann and Lavender 1999). Douglas-fir forest plantations are some of the most productive in the world (McMurtrie 1993).

Despite the importance of Douglas-fir as a plantation crop, little research has investigated how variation in LiDAR pulse density affects the predictive precision of key structural metrics. The percentage of ground returns within stands of this species is typically lower than that of other widely planted species, such as Pinus radiata D. Don (Watt et al. 2013), as Douglas-fir is typically planted at a high stand density and has a dense canopy. The percentage of ground returns is lowest immediately prior to the first thinning when stand density is highest and light penetration is very low. Paradoxically, acquisition of accurate LiDAR data during this period is likely to be very useful for predicting stand structural attributes that can be used to schedule thinning operations.

The objective of this research was to determine how reductions in LiDAR pulse density affect the prediction precision of key structural metrics for this species under two scenarios using measurements obtained from plantations of unthinned Douglas-fir. The first scenario represents an initial acquisition. Here, the point cloud was sequentially culled, the DTM recreated and point cloud metrics generated. The second scenario represents a subsequent acquisition. In this case, a DTM generated at high pulse density (10 pulses $\mathrm{m}^{-2}$ ) was used for the generation of the point cloud metrics to ensure that ground representation was accurate.

\section{Methods}

LiDAR data and stand measurements

The data used in this study were obtained from four Douglas-fir stands covering an area of 8,616 ha in the 
South Island, New Zealand (Figure 1). The LiDAR survey was flown with a fixed-wing aircraft between May and August 2012 using a small footprint $(\sim 0.20 \mathrm{~m})$ Optech ALTM 3100EA system with a swath overlap of $50 \%$. The LiDAR and flight parameters used to achieve first return densities that averaged 15.6 points $\mathrm{m}^{-2}$ (range 5.7 to 28.2 points $\mathrm{m}^{-2}$ ) are summarised in Table 1 . The system also utilised an Applanix 510 Position and Orientation System (POS) that employs a GPS and inertial measurement unit (IMU) to compensate for the aircrafts orientation, and a GPS-based computer to assist with navigation.

\section{Stand measurements}

Measurements of stand dimensions were made from July to October 2012 from systematically located plots installed across the trial area. Plots ranged in area from 0.015 to 0.1 ha. High-grade differential GPS units were used to locate the plots. All four plots containing species other than Douglas-fir were excluded from the analysis as were four plots in which the DTM was poorly defined. Plots where low pulse densities had been recorded were also excluded to ensure that the average pulse density of the plots was close to 10 pulses $\mathrm{m}^{-2}$, which was the highest pulse density used in the study. After these exclusions there were 113 plots available for the modelling (Figure 1).

Within each plot, mean diameter (at breast height; $1.4 \mathrm{~m}), D$, was recorded for all trees and heights were recorded for at least 10 trees. Stand density and basal area were determined for each plot and mean top height, $H_{\mathrm{m}}$ (height of the 100 largest diameter trees per hectare) was derived from plot mean height, $H_{\text {mean }}$, and stand density, S, using the following equation (Knowles 2003),

$$
H_{\mathrm{m}}=\left(1 / H_{\text {mean }}(1-0.106(1-\exp (-0.228(S-100) / 100)))\right)^{-1}
$$

Volume, $V$, was determined from $H_{\mathrm{m}}$ and basal area, $B$, using the following equation (Knowles 2003),

$$
V=B\left(0.928+0.3208 H_{\mathrm{m}}\right)
$$

Across the plot series there was marked variation in stand metrics and LiDAR metrics obtained at 10 pulses $\mathrm{m}^{-2}$. Mean top height, $V$ and $D$ ranged four-fold, 26-fold and three-fold across the plot series respectively, (Table 2). Ranges in LiDAR metrics were similarly marked, with the $5^{\text {th }}, 50^{\text {th }}$ and $95^{\text {th }}$ LiDAR height percentiles ranging 31fold, seven-fold, and five-fold, respectively (Table 2). Variation was also wide for the percentage of ground returns,
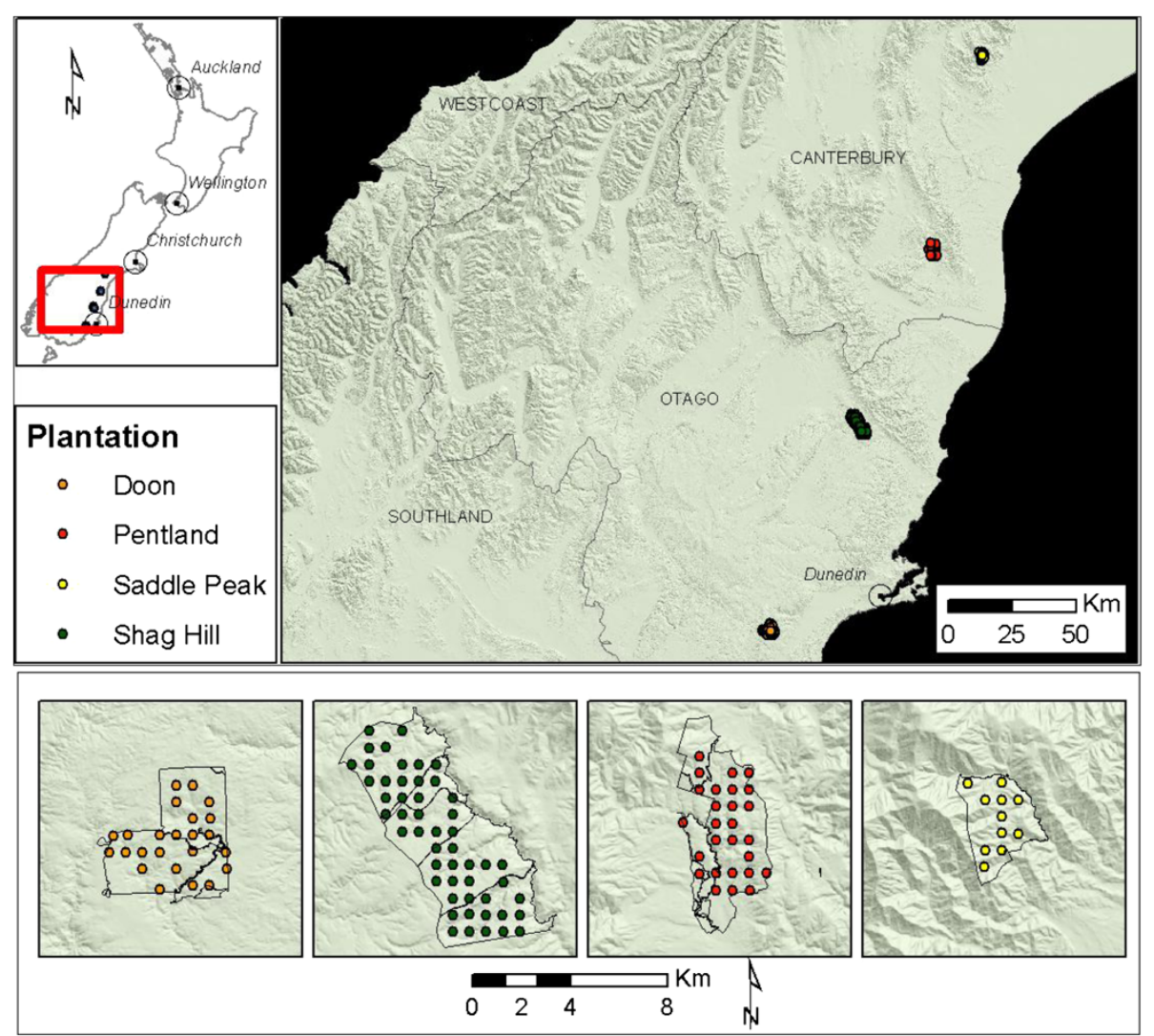

Figure 1 Map of the study area showing the distribution of the 113 plots used in the study. 
Table 1 Summary of LiDAR attributes

\begin{tabular}{ll}
\hline Variable & Value \\
\hline Wavelength $(\mathrm{nm})$ & 1064 \\
Scan angle $($ deg.) & $+/-6.1$ \\
Pulse frequency $(\mathrm{kHz})$ & 70 \\
Scan frequency $(\mathrm{Hz})$ & 70 \\
Footprint diameter $(\mathrm{m})$ & 0.19 \\
Ground speed $(\mathrm{knots})$ & 116.6 \\
Flying height $(\mathrm{m})$ & 750 \\
\hline
\end{tabular}

$\mathrm{PC}_{\mathrm{zero}}$, which averaged $3.82 \%$, ranging from $0.10-$ $20.9 \%$ (Table 2). Plot slope averaged $17^{\circ}$ and ranged from 2 to $41^{\circ}$.

\section{LiDAR processing}

LiDAR data were delivered in two sets of 115 tiled LAS formatted files. The first set contained bare-ground points and the second set contained above-ground points. Data were processed using FUSION software (McGaughey and Carson, 2003) within custom python scripts. Bare-ground and above-ground points were combined and then culled to the different pulse densities using Fusion's ThinData utility designed to produce uniform pulse density, at the specified level, across the coverage area. Digital terrain models were created for each pulse density using the culled bare-ground points.

Table 2 Variation in LiDAR and stand metrics

\begin{tabular}{|c|c|c|}
\hline Variable & Mean & Range \\
\hline \multicolumn{3}{|l|}{ LiDAR metrics } \\
\hline$H_{05}(\mathrm{~m})$ & $2.66(0.152)$ & $0.23-7.09$ \\
\hline$H_{10}(\mathrm{~m})$ & $3.22(0.159)$ & $0.46-7.65$ \\
\hline$H_{30}(\mathrm{~m})$ & $4.42(0.173)$ & $0.91-9.1$ \\
\hline$H_{50}(\mathrm{~m})$ & $5.25(0.183)$ & $1.41-9.97$ \\
\hline$H_{70}(\mathrm{~m})$ & $6.07(0.194)$ & $1.78-10.9$ \\
\hline$H_{90}(\mathrm{~m})$ & $7.22(0.210)$ & $2.34-12.3$ \\
\hline$H_{95}(\mathrm{~m})$ & $7.74(0.218)$ & $2.64-13.1$ \\
\hline$P C_{\text {zero }}(\%)$ & $3.82(0.396)$ & $0.10-20.9$ \\
\hline \multicolumn{3}{|l|}{ Stand metrics } \\
\hline Mean top height (m) & $9.70(0.241)$ & $4.31-16.0$ \\
\hline Volume $\left(\mathrm{m}^{3} \mathrm{ha}^{-1}\right)$ & $97.1(4.85)$ & $8.88-228$ \\
\hline Mean diameter (mm) & $150(3.23)$ & $65.5-229$ \\
\hline Stand density $\left(\right.$ stems ha $\left.{ }^{-1}\right)$ & $1350(46.2)$ & $383-3118$ \\
\hline Stand age (years) & $13.8(0.195)$ & $9-17$ \\
\hline
\end{tabular}

The percentage of ground returns $\left(\mathrm{PC}_{\mathrm{zero}}\right)$ was determined as the number of ground returns/(the number of ground returns + all above-ground returns).

Values shown include the mean, with standard error in brackets, and the range. All LiDAR metrics are shown for data with a pulse density of 10 pulses $\mathrm{m}^{-2}$.
Point clouds were extracted from the culled aboveground first returns within the extent of each of the 113 field plots. Depending on the scenario, all points within the point clouds were normalised to height above-ground using either the culled DTM or the DTM based on 10 pulses $\mathrm{m}^{-2}$. A set of LiDAR metrics was generated for each of the 113 sample plots using Fusion's CloudMetrics utility.

\section{Analyses}

The influence of pulse density on the quality of predictions for inventory metrics was investigated by determining the pulse density at which LiDAR derived models of $H_{\mathrm{m}}, V$, and $D$ began to substantially lose precision.

The form and statistics for the best models describing $H_{\mathrm{m}}, V$ and $D$ at the highest pulse density (pulse density = 10 returns $\mathrm{m}^{-2}$ ) are given in Table 3 . The best model for $H_{\mathrm{m}}$ used a linear form while the models for $V$ and $D$ incorporated a quadratic term as this was found to be significant. The models fitted the data well with little apparent bias (Figure 2). Precision was high for the models of $H_{\mathrm{m}}, V$ and $D$ as reflected by the high coefficients of determination which were $0.85,0.83$ and 0.73 , respectively.

The culling process reduced the pulse density from 10 to 0.01 pulses $\mathrm{m}^{-2}$ using 30 pulse densities spaced in a logarithmic progression spanning four orders of magnitude in pulse density (i.e. $10,9,8 \ldots .1,0.9,0.8 \ldots 0.1,0.09$, $0.08 \ldots .0 .01$ ). Two approaches were used for the culling process. In both approaches the pulse density of the point cloud was culled to the densities described above. In the first approach the culled point clouds were then used to create both a new DTM and corresponding LiDAR metrics. This approach was used to determine the most appropriate specification for an initial LiDAR flight. The second approach generated LiDAR metrics at all pulse densities described above using a DTM that was generated under the highest pulse density $\left(10\right.$ pulses $\left.\mathrm{m}^{-2}\right)$. This approach was used to determine the lowest pulse density at which LiDAR data can be obtained if an accurate DTM is already available. A high pulse density for the DTM was used to ensure that representation of the ground was accurate.

Table 3 Statistics and coefficients of models fitted to mean top height $\left(H_{\mathrm{m}}\right)$, volume $(V)$ and mean diameter $(D)$ for the highest pulse density (10 pulses $\mathrm{m}^{-2}$ )

\begin{tabular}{|c|c|c|c|c|c|c|}
\hline \multicolumn{2}{|c|}{ Variables in model } & \multicolumn{3}{|c|}{ Parameter values } & \multicolumn{2}{|c|}{ Model statistics } \\
\hline$y$ & $x$ & $\bar{a}$ & $\beta$ & $\lambda$ & $\overline{R^{2}}$ & RMSE \\
\hline$\overline{H_{\mathrm{m}}}$ & $H_{70}$ & 2.749 & 1.144 & - & 0.85 & $1.01 \mathrm{~m}$ \\
\hline V & $H_{10}$ & 24.41 & 16.20 & 1.561 & 0.83 & $21.3 \mathrm{~m}^{3} \mathrm{ha}^{-1}$ \\
\hline D & $H_{95}$ & 11.91 & 23.88 & -0.721 & 0.73 & $18.0 \mathrm{~mm}$ \\
\hline
\end{tabular}

Shown are the parameters ( $a, \beta$ and $\lambda$ ) for a model with the form $y=a+$ $\beta x+\lambda x^{2}$. Also shown are the coefficient of determination $\left(R^{2}\right)$ and root mean square error (RMSE) of each model. 

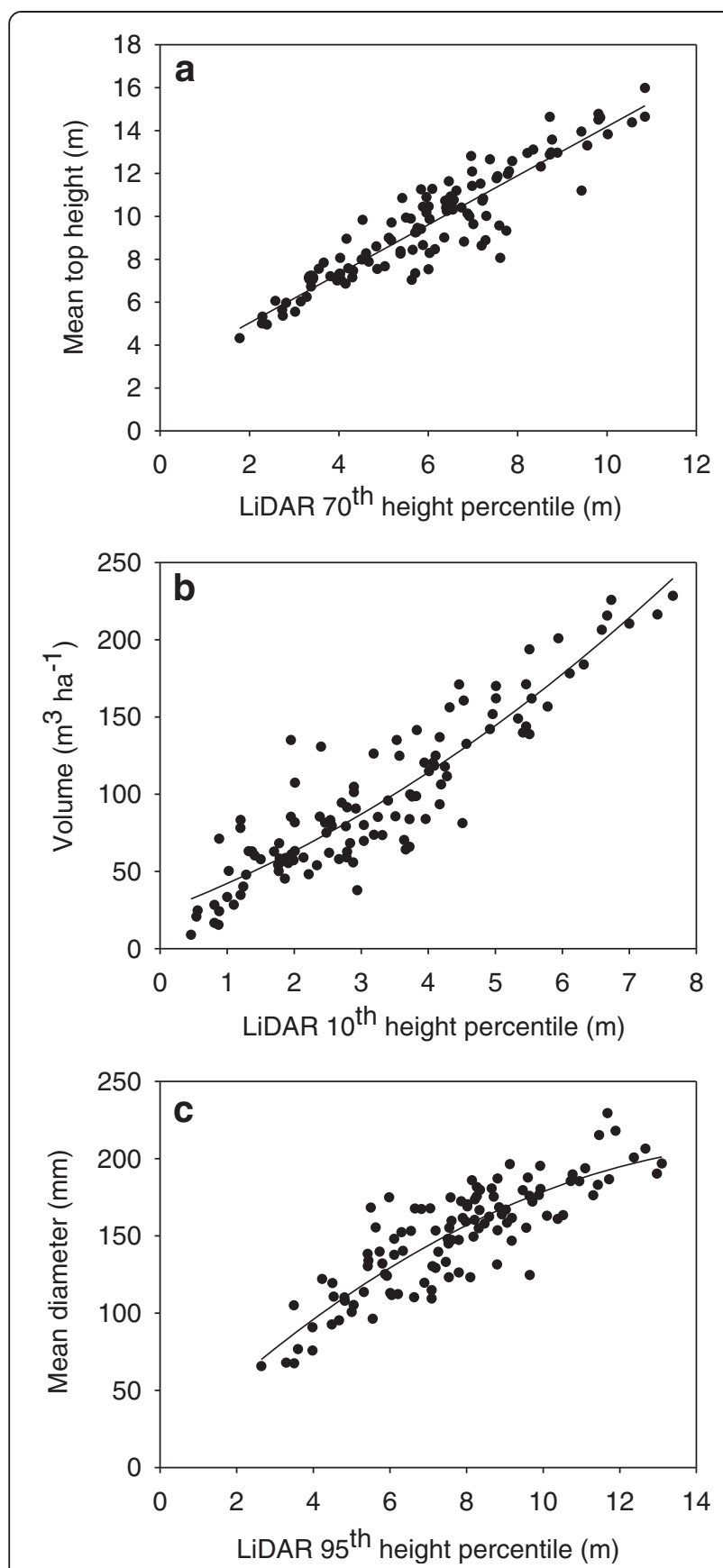

Figure 2 Relationship between LiDAR height percentiles and (a) mean top height, (b) volume or (c) mean diameter. All relationships were generated using pulse densities of 10 pulses $\mathrm{m}^{-2}$. Statistics and coefficients for the models are given in Table 3.

The three models (Table 3) were refitted at all described pulse densities for the two approaches. For each refit of the model the same independent variables were retained but coefficients were allowed to change. Statistics describing the precision of the model (coefficient of determination, $R^{2}$; root mean square error, RMSE) were extracted from each model refit and plotted against pulse density. Examination of these plots was undertaken to determine the threshold at which model precision started to decline in a systematic manner. Two pulse densities were identified, one at which $95 \%$ of the maximum $R^{2}$ was reached and the other with the maximum $R^{2}$.

Additional analysis was undertaken to determine how the quality of the underlying height metrics used in the three models deteriorated with declining pulse density. Mean plot values for the three independent variables $\left(H_{70}\right.$, $\left.H_{10}, H_{95}\right)$ at the highest pulse density were regressed against corresponding metrics determined at all lower pulse densities, for both scenarios. Assuming that height metrics for the highest pulse density are correct the RMSE for each of these regressions was determined. This RMSE was plotted against pulse density and the values at which precision of these regressions started to systematically deteriorate was identified.

\section{Results}

Influence of pulse density on equation precision

In the simulations where the same culling rates were applied to both the ground and above-ground points, the maximum $R^{2}$ was reached between 4 and 10 pulses $\mathrm{m}^{-2}$ (Figure 3; Table 4). Both the $R^{2}$ and RMSE remained reasonably static at values close to this maximum $R^{2}$ for all metrics until pulse densities of between 2 (for $H_{\mathrm{m}}$ and $D$ ) and 3 pulses $\mathrm{m}^{-2}$ (for $V$ ) were reached (Figure 3; Table 4). Below this there was a gradual decline in precision to pulse densities of $c a .1 .0$ for $H_{\mathrm{m}}$ and $V$ and 0.7 pulses $\mathrm{m}^{-2}$ for $D$, at which point the $R^{2}$ was $95 \%$ of maximum values (Figure 3; Table 4). Further culling of the data resulted in a sharp decline in model precision for all metrics (Figure 3 ).

The precision of the three models remained higher where the DTM generated at a pulse density of 10 pulses $\mathrm{m}^{-2}$ was used throughout the culling process. Although the maximum $R^{2}$ were found at relatively low pulse densities $\left(0.3\right.$ pulses $\left.\mathrm{m}^{-2}\right)$ for two of the three metrics, little variation in precision of the culled metrics was noted from 10 pulses $\mathrm{m}^{-2}$ to a threshold of 0.04 pulses $\mathrm{m}^{-2}$ for $D$ and 0.2 pulses $\mathrm{m}^{-2}$ for $H_{\mathrm{m}}$ and $V$ (Figure 3; Table 4). The point at which the $R^{2}$ reached $95 \%$ of maximum values was 0.06, 0.1 and 0.04 pulses $\mathrm{m}^{-2}$, respectively, for $H_{\mathrm{m}}, V$ and $D$ (Figure 3; Table 4). A rapid decline in precision was noted below pulse densities of 0.04 pulses $\mathrm{m}^{-2}$ for all three stand metrics. Relative changes in RMSE were very similar to those noted for the $R^{2}$ for both scenarios (Figure 3 ).

\section{Influence of pulse density on LiDAR height metrics}

Examination of the effect of culling on error of the height metrics underlying the three regression equations showed considerable variation between the two types of simulation (Figure 4). For the simulations where the DTM was 


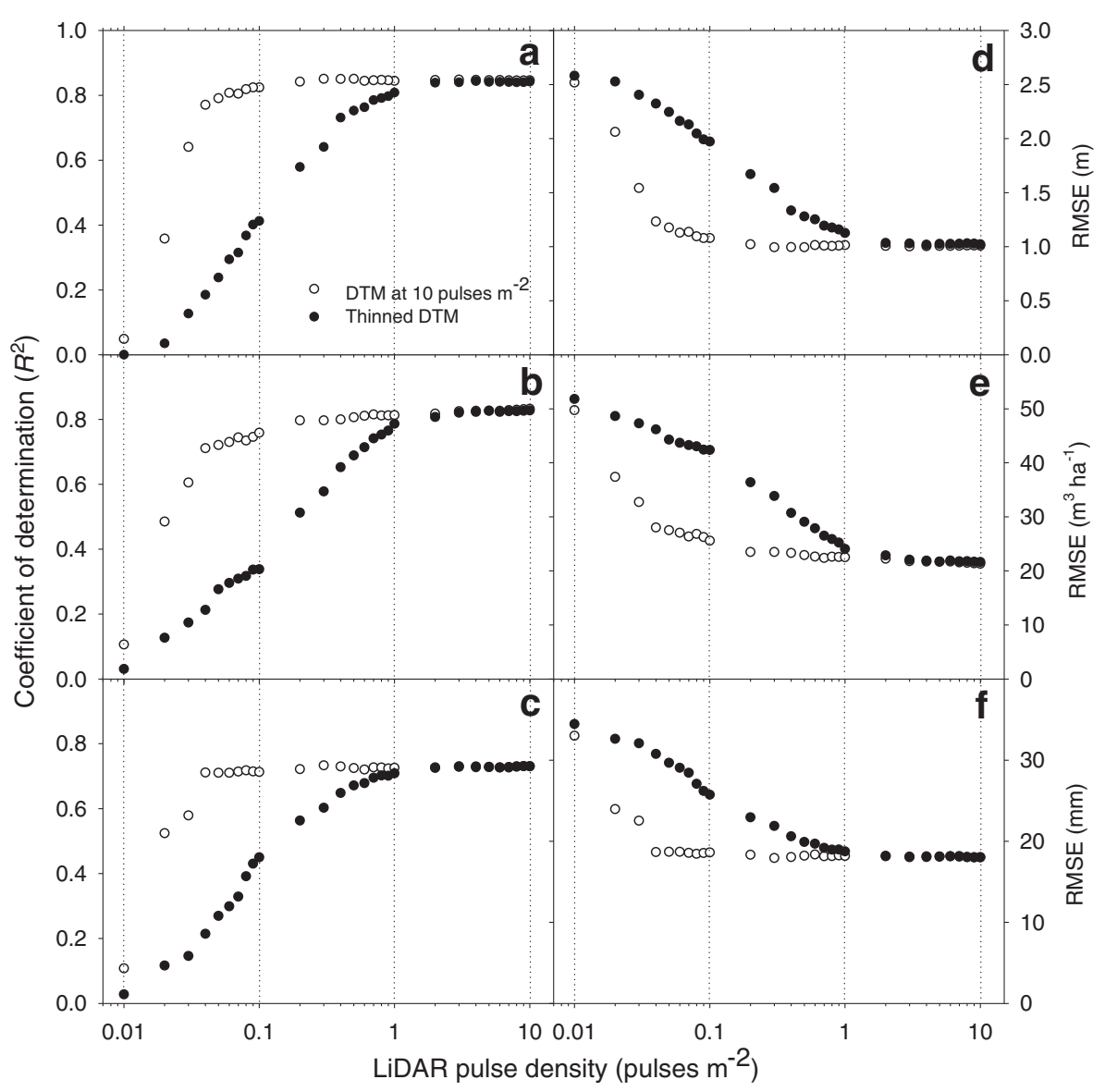

Figure 3 Relationship between LiDAR pulse density and coefficient of determination (left side) and root mean square error (right side) for $(\mathbf{a}, \mathbf{d})$ mean top height, $(\mathbf{b}, \mathbf{e})$ volume and $(\mathbf{c}, \mathbf{f})$ mean diameter. Closed circles denote values for the culled DTM while open circles denote values for the DTM held at a pulse density of 10 pulses $\mathrm{m}^{-2}$ throughout the culling process. The $x$-axis is displayed using a logarithmic scale with dotted lines vertically connecting values of $0.01,0.1,1$ and 10 pulses $\mathrm{m}^{-2}$.

culled, RMSE increased relatively slowly as pulse density declined until a pulse density of 1 pulse $\mathrm{m}^{-2}$ was reached. At this point RMSE was $c a .0 .5 \mathrm{~m}$ for all three height metrics (Figure 4). As pulse densities declined below this point, there was a marked increase in the RMSE (Figure 4). In simulations with a DTM generated at a high pulse density, RMSE declined far more slowly and did not reach $0.5 \mathrm{~m}$ until a pulse density of $c a .0 .06$ pulses $\mathrm{m}^{-2}$ was reached for all three metrics (Figure 4). There was a marked increase in RMSE at pulse densities below 0.04 pulses $\mathrm{m}^{-2}$ (Figure 4).

The corresponding RMSE in the height metrics for the pulse densities at which $95 \%$ of the maximum $R^{2}$ (see Table 4) was reached was greater for $H_{95}$ than the other two height metrics. For simulations where the DTM was culled and held at 10 pulses $\mathrm{m}^{-2}$, RMSE values were respectively, 0.56 and $0.45 \mathrm{~m}$ for $H_{70}, 0.47$ and 0.42 for $H_{10}$, and 0.71 and $0.63 \mathrm{~m}$ for $H_{95}$ (Figure 4).

Table 4 Variation in pulse densities required to obtain the maximum coefficient of determination $\left(\max . R^{2}\right)$, the threshold $R^{2}$ and $95 \%$ of the maximum $R^{2}\left(95 \%\right.$ max. $\left.R^{2}\right)$ for mean top height $\left(H_{\mathrm{m}}\right)$, volume $(V)$ and mean diameter at breast height $(D)$

\begin{tabular}{|c|c|c|c|c|c|c|}
\hline \multirow[t]{2}{*}{ Stand metric } & \multicolumn{3}{|c|}{ Culled DTM } & \multicolumn{3}{|c|}{ DTM at 10 pulses $\mathrm{m}^{-2}$} \\
\hline & $R^{2}$ max. & $R^{2}$ threshold. & $95 \% R^{2} \max$ & $R^{2} \max$. & $R^{2}$ threshold. & $95 \% R^{2} \max$. \\
\hline$H_{\mathrm{m}}$ & 4 & 2 & 0.9 & 0.3 & 0.2 & 0.06 \\
\hline V & 10 & 3 & 1 & 10 & 0.2 & 0.1 \\
\hline D & 10 & 2 & 0.7 & 0.3 & 0.04 & 0.04 \\
\hline
\end{tabular}

Simulations are shown where the DTM was culled and held at a pulse density of 10 pulses $\mathrm{m}^{-2}$ throughout the culling process. 


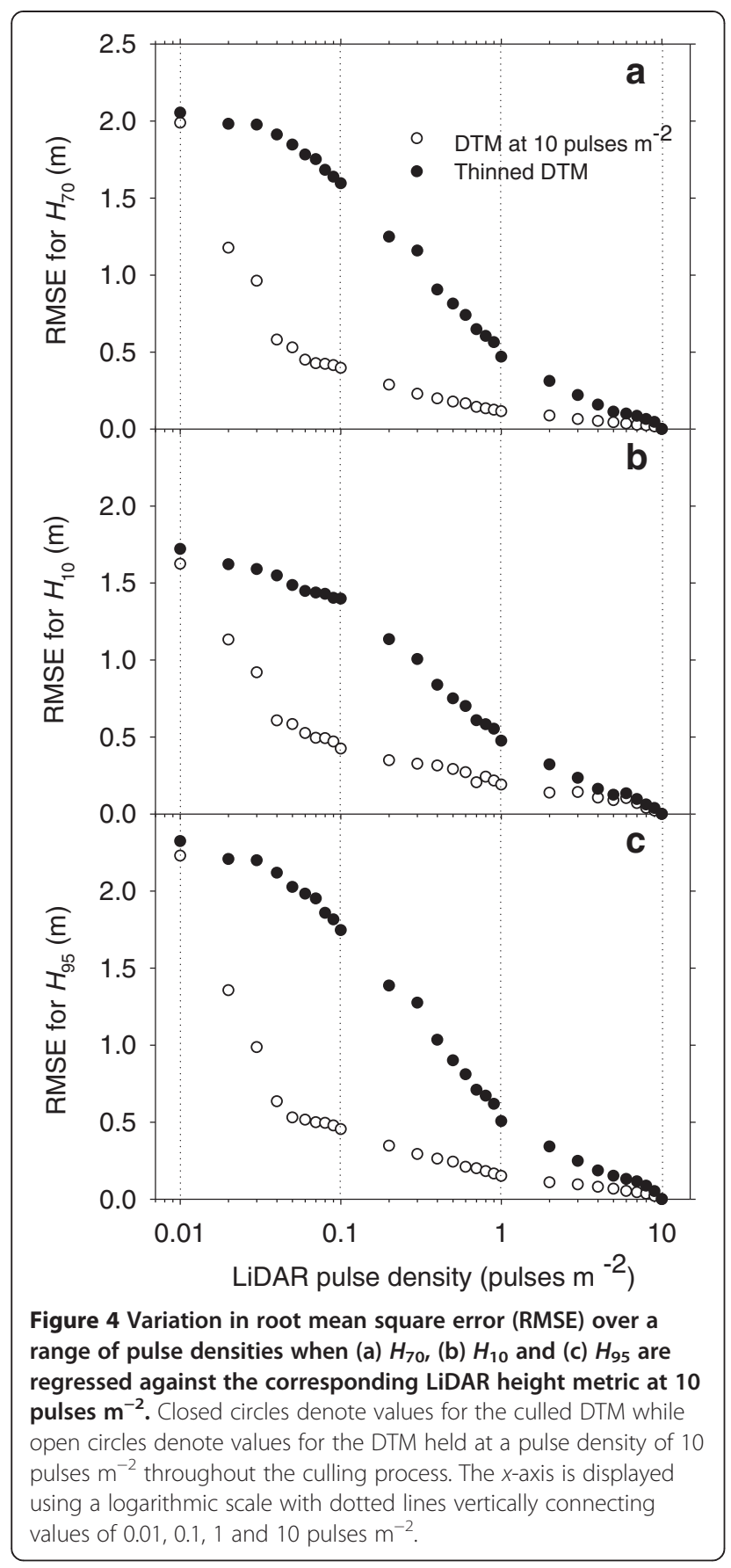

\section{Discussion}

The quality of the DTM had a major effect on precision of the three regression equations. Use of a high-quality DTM allowed pulse densities to be reduced to between $0.04-$ 0.2 pulses $\mathrm{m}^{-2}$ before predictive precision started to decline. These pulse densities were at least an order of magnitude lower than the thresholds of $2-3$ pulses $\mathrm{m}^{-2}$ for the simulations where the DTM was culled. These results agree with previous research where changes in predictive precision of tree height and volume with declining pulse density were quantified for simulations that used a high quality and culled DTM (Magnusson et al. 2010).

The difference in predictive precision between the two scenarios was attributed to deteriorating DTM quality. The quality of a DTM derived from laser data is affected by several factors including the classification parameters set by the survey company, interpolation method and grid size. As these factors were kept constant in the current study, the quality of the culled DTM was due to a reduction in the density of ground returns compared to the DTM generated at a high pulse density. This reduction in point density leads to increasing classification and interpolation errors (Anderson et al. 2006). Classification errors became more marked as the culling intensity increased as reflected by the increasing percentage of classified ground returns observed in the culled DTM from 3.82 at 10 pulses $\mathrm{m}^{-2}$ to $4.42 \%$ at 1 pulse $\mathrm{m}^{-2}$ to $24.3 \%$ at 0.01 pulses $\mathrm{m}^{-2}$.

Predictive precision of $D$ remained stable to lower pulse densities under both scenarios than precision of equations for $H_{\mathrm{m}}$ and $V$. This was particularly marked for simulations with the high quality DTM where both the threshold and $95 \%$ of the maximum $R^{2}$ for predictions of $D$ occurred at 0.04 pulses $\mathrm{m}^{-2}$. For simulations with the high quality DTM changes in RMSE for the underlying LiDAR height metrics with pulse density were very similar among the three stand dimensions (Figure 4). This disparity in stability at low pulse density was therefore attributed to the higher precision of the base equations for $H_{\mathrm{m}}\left(R^{2}=0.85\right)$ and $V\left(R^{2}=0.83\right)$ that were more sensitive to increasing error in the underlying height metric than the less precise equation developed for $D\left(R^{2}=0.73\right)$. Comparison of the RMSE for the underlying LiDAR metric at which $95 \%$ of the maximum $R^{2}$ was reached confirmed this by showing that RMSE was markedly higher at this point for the prediction of $D$ than either $H_{\mathrm{m}}$ or $V(0.63 \mathrm{~m} v s .0 .45$ and $0.42 \mathrm{~m}$ ). A similar, although less pronounced, effect was observed for predictions of the three stand dimensions for the culled DTM.

Currently most LiDAR in New Zealand are acquired within Pinus radiata planted data forests at a pulse density of between 1-2 pulses $\mathrm{m}^{-2}$ (New Zealand Aerial Mapping pers. comm.). Results from this study suggest that pulse densities of 2-3 pulses $\mathrm{m}^{-2}$ would be suitable for young unthinned Douglas-fir plantations during initial acquisition when an accurate DTM is not usually available. For Douglas-fir stands that have an accurate DTM, pulse densities could be reduced to $c a .0 .2$ pulses $\mathrm{m}^{-2}$ without unduly compromising predictive precision of canopy metrics. It is likely that pulse densities during a subsequent acquisition could be reduced to 0.2 pulses $\mathrm{m}^{-2}$ when an initial acquisition is undertaken at 2-3 pulses $\mathrm{m}^{-2}$ as equation precision between this pulse density 
and 10 pulses $\mathrm{m}^{-2}$ was very similar for the first scenario. It should be noted that these minimum pulse densities correspond to LiDAR acquired with a repetition rate of $70 \mathrm{kHz}$, which is $70 \%$ of the instrument range of $100 \mathrm{kHz}$. Reducing the laser repetition rate distributes the available energy over fewer pulses. This setting was used in this data acquisition to increase the probability that pulses had sufficient energy to penetrate the dense Douglas-fir canopy to the ground.

In an operational setting pulse density and LiDAR acquisition cost can be reduced through flying faster, reducing the swath overlap or flying at higher altitude. Increases in aircraft speed or a reduction in the swath overlap will reduce the pulse density without influencing other specifications such as footprint diameter and ability of the laser to penetrate the canopy (Magnusson et al. 2010).

In contrast, flying at a higher altitude affects several features of the data. The footprint diameter and swath width increase while the reflected energy, ability of the laser to penetrate the canopy, and maximum pulse repetition frequency decline (Magnusson et al. 2010). As a result of these changes flying at higher altitude results in a change in the distribution of echo categories, an upward shift in the canopy-height distribution and a lower proportion of multiple returns (Goodwin et al. 2006; Næsset 2004a, 2009). Although changes to these latter features do not significantly affect the precision of regression equations for common stand dimensions (basal area, volume or mean tree height) coefficients in the regression equations are likely to change between acquisitions at different altitudes (Næsset 2004a, 2009).

The very low percentage of ground returns recorded in this dataset provided a robust test of how far LiDAR pulse density could be reduced without affecting model precision. Compared with previous research, the mean percentage of ground returns recorded here (3.82\%) was markedly lower that the typical range $(11-33 \%)$ found for other coniferous species (Næsset 2002; Næsset and Bjerknes 2001; Næsset 2004a) but was quite similar to that recorded for highly stocked unthinned hinoki cypress (Chamaecyparis obtusa Sieb. et Zucc.) and sugi (Cryptomeria japonica D. Don) plantations where values for the two species were, respectively, 1.1 and $8.1 \%$ (Takahashi et al. 2006). The low penetration rates in this study are likely to be attributable to the dense closed canopy of the plantations and the topographically complex terrain over which the study sites were located. Culling LiDAR to lower pulse densities may be possible in more open stands of Douglas-fir without compromising the precision of relationships between LiDAR and key structural metrics. As these results are conservative, use of the information obtained from this study to guide LiDAR specifications is likely to result in acquisition of higher quality datasets.

\section{Conclusion}

Results show that during an initial acquisition when an accurate DTM has not been defined LiDAR pulse densities can be reduced to $2-3$ pulses $\mathrm{m}^{-2}$ without markedly reducing the precision of relationships between LiDAR metrics and stand dimensions. However, results show that pulse densities can be reduced to values as low as $0.04-0.2$ pulses $\mathrm{m}^{-2}$ without substantial precision losses in these relationships if an accurate DTM is available. As these results were obtained from highly stocked unthinned stands they are likely to provide conservative guidelines for LiDAR acquisition within Douglas-fir stands.

\section{Competing interests}

The authors declare that they have no competing interests.

\section{Authors' contributions}

MSW was the primary author and undertook all analyses. AM processed the LiDAR data, extracted metrics and produced the maps. PW assisted with the writing and provision of technical detail. AG assisted with the writing, developed the specification for the LiDAR and provided the plot data. All authors read and approved the final manuscript.

\section{Acknowledgements}

We are grateful to Blakely Pacific Ltd for providing the LiDAR dataset on which this study is based.

\section{Author details}

${ }^{1}$ Scion, PO Box 29237, Fendalton, Christchurch, New Zealand. ${ }^{2}$ Indufor Asia-Pacific Ltd, PO Box 105039, Auckland, New Zealand. ${ }^{3}$ Blakely Pacific Ltd, PO Box 13-980, Christchurch 8141, New Zealand.

Received: 15 September 2013 Accepted: 27 June 2014

Published online: 07 August 2014

\section{References}

Anderson, ES, Thompson, JA, Crouse, DA, \& Austin, RE. (2006). Horizontal resolution and data density effects on remotely sensed LIDAR-based DEM. Geoderma, 132(3-4), 406-415.

Baltsavias, EP. (1999). Airborne laser scanning: basic relations and formulas. Isprs Journal of Photogrammetry and Remote Sensing, 54(2-3), 199-214.

Coops, NC, Hilker, T, Wulder, MA, St-Onge, B, Newnham, G, Siggins, A, \& Trofymow, JA. (2007). Estimating canopy structure of Douglas-fir forest stands from discrete-return LiDAR. Trees-Structure and Function, 21, 295-310.

Gobakken, T, \& Naesset, E. (2008). Assessing effects of laser point density, ground sampling intensity, and field sample plot size on biophysical stand properties derived from airborne laser scanner data. Canadian Journal of Forest Research-Revue Canadienne De Recherche Forestiere, 38(5), 1095-1109. doi: 10.1139/X07-219.

Goodwin, NR, Coops, NC, \& Culvenor, DS. (2006). Assessment of forest structure with airborne LiDAR and the effects of platform altitude. Remote Sensing of Environment, 103(2), 140-152.

Hall, SA, Burke, IC, Box, DO, Kaufmann, MR, \& Stoker, JM. (2005). Estimating stand structure using discrete-return lidar: an example from low density, fire prone ponderosa pine forests. Forest Ecology and Management, 208(1-3), 189-209.

Hermann, RK, \& Lavender, DP. (1999). Douglas-fir planted forests. New Forests, 17(1-3), 53-70. doi:10.1023/A:1006581028080.

Jakubowski, MK, Guo, QH, \& Kelly, M. (2013). Tradeoffs between lidar pulse density and forest measurement accuracy. Remote Sensing of Environment, 130, 245-253. doi:10.1016/j.rse.2012.11.024.

Knowles, L. (2003). Calculators for radiata pine and Douglas fir. New Zealand Tree Grower, 24(2), 26-27.

Lovell, JL, Jupp, DLB, Newnham, GJ, Coops, NC, \& Culvenor, DS. (2005). Simulation study for finding optimal lidar acquisition parameters for forest height retrieval. Forest Ecology and Management, 214(1-3), 398-412. doi:10.1016/j. foreco.2005.07.077. 
Magnusson, M, Fransson, JES, \& Holmgren, J. (2010). Effects of estimation accuracy of forest variables using different pulse density of laser data. Forest Science, 53, 619-626.

McGaughey, RJ, \& Carson, WW. (2003). Fusing LIDAR data, photographs, and other data using $2 \mathrm{D}$ and $3 \mathrm{D}$ visualization techniques. In Proceedings of Terrain Data: Applications and Visualization-Making the Connection; October 28-30, 2003; Charleston, South Carolina: Bethesda, MD: American Society for Photogrammetry and Remote Sensing 16-24.

McMurtrie, RE. (1993). Modelling of canopy carbon and water balance. In DO Hall, JMO Scurlock, HR Bolhar-Nordenkampf, RC Leegood, \& SP Long (Eds.), Photosynthesis and production in a changing environment: a field and laboratory manual (pp. 220-231). London: Chapman and Hall.

Means, JE, Acker, SA, Harding, DJ, Blair, JB, Lefsky, MA, Cohen, WB, Harmon, ME, \& McKee, WA. (1999). Use of large-footprint scanning airborne LiDAR to estimate forest stand characteristics in the Western Cascades of Oregon. Remote Sensing of Environment, 67(3), 298-308.

Means, JE, Acker, SA, Fitt, BJ, Renslow, M, Emerson, L, \& Hendrix, CJ. (2000). Predicting forest stand characteristics with airborne scanning LiDAR. Photogrammetric Engineering And Remote Sensing, 66(11), 1367-1371.

Næsset, E. (2002). Predicting forest stand characteristics with airborne scanning laser using a practical two-stage procedure and field data. Remote Sensing of Environment, 80(1), 88-99.

Næsset, E. (2004a). Effects of different flying altitudes on biophysical stand properties estimated from canopy height and density measured with a small-footprint airborne scanning laser. Remote Sensing of Environment, 92, 243-255.

Næsset, E. (2004b). Practical large-scale forest stand inventory using a small-footprint airborne scanning laser. Scandinavian Journal of Forest Research, 19(2), 164-179. doi: 10.1080/02827580310019257.

Næsset, E. (2005). Assessing sensor effects and effects of leaf-off and leaf-on canopy conditions on biophysical stand properties derived from small-footprint airborne laser data. Remote Sensing of Environment, 98(2-3), 356-370.

Næsset, E. (2009). Effects of different sensors, flying altitudes, and pulse repetition frequencies on forest canopy metrics and biophysical stand properties derived from small-footprint airborne laser data. Remote Sensing of Environment, 113(1), 148-159. doi: 10.1016/j.rse.2008.09.001.

Næsset, E, \& Bjerknes, KO. (2001). Estimating tree heights and number of stems in young forest stands using airborne laser scanner data. Remote Sensing of Environment, 78(3), 328-340.

Næsset, E, \& Okland, T. (2002). Estimating tree height and tree crown properties using airborne scanning laser in a boreal nature reserve. Remote Sensing of Environment, 79(1), 105-115.

Nelson, R, Krabill, W, \& MacLean, G. (1984). Determining forest canopy characteristics using airborne laser data. Remote Sensing of Environment, $15,201-212$

Nord-Larsen, T, \& Schumacher, J. (2012). Estimation of forest resources from a country wide laser scanning survey and national forest inventory data. Remote Sensing of Environment, 119, 148-157. doi: 10.1016/..rse.2011.12.022.

Takahashi, T, Yamamoto, K, Miyachi, Y, Senda, Y, \& Tsuzuku, M. (2006). The penetration rate of laser pulses transmitted from a small-footprint airborne LiDAR: a case study in closed canopy, middle-aged pure sugi (Cryptomeria japonica D. Don) and hinoki cypress (Chamaecyparis obtusa Sieb. et Zucc.) stands in Japan. Journal of Forest Research, 11(2), 117-123.

Treitz, P, Lim, K, Woods, M, Pitt, D, Nesbitt, D, \& Etheridge, D. (2012). LiDAR sampling density for forest resource inventories in Ontario, Canada. Remote Sensing, 4(4), 830-848. doi: 10.3390/Rs4040830.

Watt, PJ, \& Watt, MS. (2013). Development of a national model of Pinus radiata stand volume from LiDAR metrics for New Zealand. International Journal of Remote Sensing 34, 5892-5904.

Watt, MS, Adams, T, Watt, P, \& Marshall, H. (2013). Influence of stand and site conditions on the quality of digital elevation models underlying New Zealand forests. New Zealand Journal of Forestry Science, 43, 39-47.

doi:10.1186/s40490-014-0018-3

Cite this article as: Watt et al:: The influence of LiDAR pulse density on the precision of inventory metrics in young unthinned Douglas-fir stands during initial and subsequent LiDAR acquisitions. New Zealand Journal of Forestry Science 2014 44:18.

\section{Submit your manuscript to a SpringerOpen ${ }^{\circ}$ journal and benefit from:}

- Convenient online submission

- Rigorous peer review

- Immediate publication on acceptance

- Open access: articles freely available online

- High visibility within the field

- Retaining the copyright to your article

Submit your next manuscript at $>$ springeropen.com 